\title{
$\mu$-BENZENE-1,2,4,5-TETRACARBOXYLATO- $\left.\kappa^{2} \mathrm{O}^{1}: \mathrm{O}^{4}\right)$ BIS-[AQUA-BIS-2-(AMINOMETHYL) PYRIDINE-k²N,N') NICKEL (II)] DECAHYDRATE: STRUCTURE AND MAGNETIC PROPERTIES \#
}

\author{
ANA MARÍA ATRIA*l, JOSÉ PARADA ${ }^{1}$, RICARDO BAGGIO², OCTAVIO PEÑA ${ }^{3}$, YANKO MORENO** \\ ${ }^{1}$ Facultad de Ciencias Químicas y Farmacéuticas, Universidad de Chile. Santiago, Chile. \\ ${ }^{2}$ Gerencia de Investigación y Aplicaciones, Centro Atómico Constituyentes, Comisión Nacional de Energía Atómica, Buenos Aires, \\ Argentina. \\ ${ }^{3}$ Univ Rennes, CNRS, ISCR [(Institut des Sciences Chimiques de Rennes)] - UMR 6226, F-35000 Rennes, France. \\ ${ }^{4}$ Universidad Andres Bello, Departamento de Ciencias Quimicas, Facultad de Ciencias Exactas, CP2520000, Viña del Mar, Chile.
}

\#. Recognition : this work is dedicated to the memory of our colleague, Dr. Jean-Yves Pivan (1955-2018).

\section{ABSTRACT}

$\mu$-Benzene-1,2,4,5-tetracarboxylato- $\left.\kappa^{2} \mathrm{O}^{1}: \mathrm{O}^{4}\right)$ bis-[aqua-bis-2-(aminomethyl) pyridine- $\left.\kappa^{2} \mathrm{~N}_{2} \mathrm{~N}^{\prime}\right)$ nickel $\left.(\mathrm{II})\right]$ decahydrate, $\left[\mathrm{Ni}_{2}(a m p)_{4}(\right.$ btc $\left.)\left(\mathrm{H}_{2} \mathrm{O}\right)_{2}\right] \cdot 10 \mathrm{H}_{2} \mathrm{O}$ has been synthesized and its crystal structure determined by X-ray diffraction. The complex crystallizes in the Monoclinic space group $P 2_{1} / n$ with cell dimensions a $=11.0102$ (10) $\AA, b=21.5416$ (19) $\AA, c=11.0445$ (10) $\AA$ and $\beta=118.753(1)^{\circ}$, and two formula units per cell $\left(Z=2, Z^{\prime}=0.5\right)$.

The structure consists of centrosymmetric dimeric units in which the benzene tetracarboxylate anions (btc) bridge the symmetry-related nickel (II) cations, two bidentate chelating molecules of 2-(aminomethyl) pyridine and a terminal aqua ligand completing the six-fold coordination at each metal. These dimers link to each other via H-bonding to form chains parallel to [100], while the water solvates form a strongly bound $2 \mathrm{D}$ network parallel to $(100)$, made up by small ( $\left.\mathrm{R}_{4}^{4}(8)\right)$ and large $\left(\mathrm{R}^{20}{ }_{20}(40)\right)$ rings, the latter ones "pierced" by the chains of dimmers, with a profuse H-bonding interconnection between both substructures.

Magnetic susceptibility measurements as a function of temperature disclose weak interdimeric exchange interactions. Fitting of these data to a dimeric model yields $\mathrm{J}=-3.5 \mathrm{~cm}^{-1}$ and $\mathrm{g}=2.13$.

Keywords: crystal structure, nickel complex, magnetism.

\section{INTRODUCTION}

Coordination chemistry is one of the most important and active research areas in Inorganic Chemistry. This interest can not only be explained by the different crystal structures and spatial arrangements presented by the coordination compounds, but also by the different properties exhibited by such compounds (magnetic, optical, electronic, etc.) and their applications in various fields [1-4].

In the formulation of coordination compounds the metal center plays an important role, and also the ligands. From the structural point of view, the multicarboxylate ligands are extremely interesting due to the different dimensions and topologies they can produce in the resulting compounds. One example is the benzene-1,2,4,5-tetracarboxylic acid, presenting eight possible active sites available for coordination and a variety of modes of union, either bridging, chelating or a mixture of both, due to the large degree of rotational freedom of its four carboxylate groups [5-8].

Regarding magnetism, some common features linking structure and magnetic behavior have been relatively well established over the years, mainly when the carboxylate acts in a bridging mode, viz., complexes that present monoatomic or syn-anti bridges (Scheme 1) which usually show weak antiferromagnetic interactions, in contrast with those in which the carboxylate bridge is in a syn-syn form, where the interaction is mostly strong and antiferromagnetic. On the other hand, anti-anti modes are not so determinant, as they may produce either ferro- or antiferromagnetic coupling [9-12].<smiles>[M]OC(P)O[Na]</smiles>

syn-syn

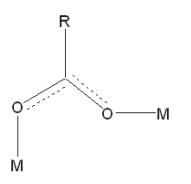

syn-anti

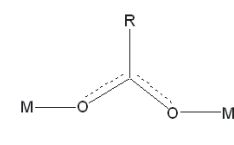

anti-anti

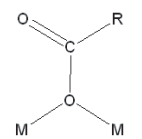

mono atomic
Scheme 1 .

Pursuing our interest in the correlation of structural and magnetic properties of transition metal complexes, we have prepared a new dimeric $\mathrm{Ni}$ (II) complex with 2-(aminomethyl) pyridine ( $\mathrm{amp}$ ) and benzene-1,2,4,5-tetracarboxylic acid
$\left(H_{4} b t c\right)$, formulated as $\left[\mathrm{Ni}_{2}(a m p)_{4}(\mathrm{btc})\left(\mathrm{H}_{2} \mathrm{O}\right)_{2}\right] \cdot 10 \mathrm{H}_{2} \mathrm{O}(\mathbf{1})$, (Scheme 2), where the link between metal centres does not go through either of the bridging types presented in Scheme 1, but runs instead through the whole btc intradimeric ligand, leaving both $\mathrm{Ni}(\mathrm{II})$ centres aside, at a rather large distance for any significant magnetic interaction. Our analysis will show, however, that some relevant magnetic properties may arise in spite of this seemingly unfavourable geometry, mainly due to the profuse interdimeric H-bonding network present.

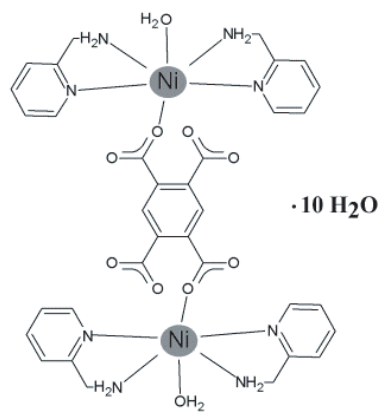

Scheme 2.

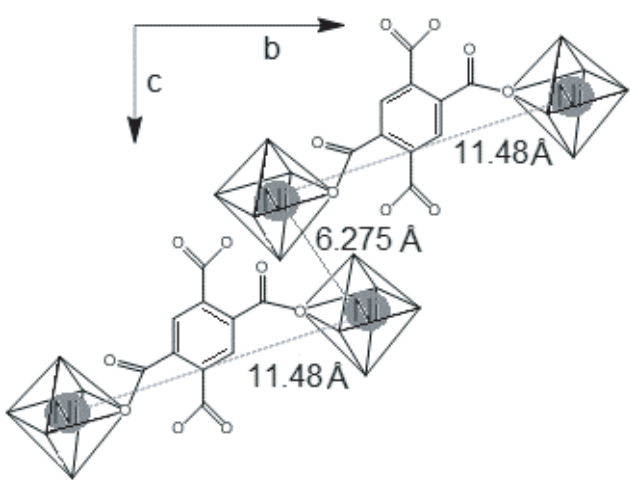

Scheme 3 . 


\section{EXPERIMENTAL}

\subsection{Materials}

All reagents and solvents employed were commercially available and used as received without further purification.

\subsection{Synthesis}

For the synthesis of complex (1), benzene-1,2,4,5-tetracarboxylic acid $\left(\mathrm{H}_{4}\right.$ btc; $\left.0.254 \mathrm{~g}, 1 \mathrm{mmol}\right)$ was slowly added to an aqueous solution $(20 \mathrm{~mL})$ of $\mathrm{NaOH}$ (0.16 g, $4 \mathrm{mmol})$. Nickel acetate tetrahydrate $(0.497 \mathrm{~g}, 2 \mathrm{mmol})$ was dissolved in water $(20 \mathrm{~mL})$ and added to the above solution. The resulting mixture was stirred for $10 \mathrm{~min}$, followed by the addition of a methanolic solution (15 mL) of 2-(aminomethyl)pyridine (amp; $206 \mu \mathrm{L}, 2 \mathrm{mmol}$ ) and the mixture was refluxed for $4 \mathrm{~h}$ and then cooled to room temperature.

Single crystals of (1), suitables for X-ray diffraction studies, were obtained by slow solvent evaporation.

\subsection{Crystallography}

The diffraction data set was collected up to a $2 \Theta \max$ of $58^{\circ}$ using monochromatic Mo $\mathrm{K} \alpha$ radiation, $\lambda=0.7107 \AA, \mathrm{T}=150 \mathrm{~K}$ on a Bruker Smart diffractometer. The following softwares were used in different stages of the crystal structure analysis process:

Data collection: SMART; cell refinement: SAINT; data reduction: SAINT; program(s) used to solve structure: SHELXS97; $\operatorname{program}(\mathrm{s})$ used to refine structure: SHELXL2014/6; Molecular graphics: SHELXTL; software used to prepare material for publication: SHELXTL [13-16]. Crystal data, data collection and structure refinement details are summarized in Table 1.

Table 1: Experimental details

\begin{tabular}{|c|c|}
\hline \multicolumn{2}{|l|}{ Crystal data } \\
\hline Chemical formula & $\mathrm{C}_{34} \mathrm{H}_{38} \mathrm{~N}_{8} \mathrm{Ni}_{2} \mathrm{O}_{10} \cdot 10\left(\mathrm{H}_{2} \mathrm{O}\right)$ \\
\hline$M_{\mathrm{r}}$ & 1016.26 \\
\hline Crystal system, space group & Monoclinic, $P 2_{1} / n$ \\
\hline Temperature $(\mathrm{K})$ & 150 \\
\hline$a, b, c(\AA)$ & $\begin{array}{llll}\begin{array}{l}11.0102 \\
(10)\end{array} & (10), 21.5416 \text { (19), } 11.0445 \\
\end{array}$ \\
\hline$\beta\left(^{\circ}\right)$ & $118.753(1)$ \\
\hline$V\left(\AA^{3}\right)$ & $2296.5(4)$ \\
\hline$Z$ & 2 \\
\hline Radiation type & Mo $K \alpha$ \\
\hline$\mu\left(\mathrm{mm}^{-1}\right)$ & 0.90 \\
\hline Crystal size (mm) & $0.48 \times 0.23 \times 0.21$ \\
\hline \multicolumn{2}{|l|}{ Data collection } \\
\hline Diffractometer & $\begin{array}{l}\text { Bruker CCD area detector } \\
\text { diffractometer }\end{array}$ \\
\hline Absorption correction & $\begin{array}{l}\text { Multi-scan } \\
\text { SADABS (Sheldrick, 2001) }\end{array}$ \\
\hline $\begin{array}{l}\text { No. of measured, independent and } \\
\text { observed }[I>2 \sigma(I)] \text { reflections }\end{array}$ & $18937,5066,4641$ \\
\hline$R_{\text {int }}$ & 0.022 \\
\hline$(\sin \theta / \lambda)_{\max }\left(\AA^{-1}\right)$ & 0.659 \\
\hline \multicolumn{2}{|l|}{ Refinement } \\
\hline$R\left[F^{2}>2 \sigma\left(F^{2}\right)\right], w R\left(F^{2}\right), S$ & $0.035,0.087,1.09$ \\
\hline No. of reflections & 5066 \\
\hline No. of parameters & 337 \\
\hline No. of restraints & 81 \\
\hline H-atom treatment & $\begin{array}{l}\mathrm{H} \text { atoms treated by a mixture of } \\
\text { independent and constrained refinement }\end{array}$ \\
\hline$\left.\Delta\rangle_{\max }, \Delta\right\rangle_{\min }\left(\mathrm{e} \AA^{-3}\right)$ & $0.53,-0.23$ \\
\hline
\end{tabular}

\subsection{Magnetic measurements}

Magnetic susceptibility measurements were performed in the temperature range 2-300 K, using a Quantum Design MPMS XL5 SQUID Susceptometer, with an applied field of 1000 Oe. Measurements were performed on a powder sample of (1) encapsulated on a gelatin container. The magnetic data were corrected for the diamagnetism of the constituent atoms from the Pascal's constants [17].

\section{Results and discussion}

Crystal data, data collection and structure refinement details for the $\left[\mathrm{Ni}_{2}(a m p)_{4} \quad(\right.$ btc $\left.)\left(\mathrm{H}_{2} \mathrm{O}\right)_{2}\right] \cdot 10 \mathrm{H}_{2} \mathrm{O}(\mathbf{1}) \quad$ complex, where $a m p=2$ amino-methyl-pyridine and $b t c=$ Benzene-1,2,4,5-tetracarboxylate anion, are summarized in Table 1 . Table 2 provides a selection of coordination parameters while Table 3 shows the most significant H-bonding interactions in the structure.

Table 2: Selected geometric parameters $\left(\AA,^{\circ}\right)$

\begin{tabular}{|l|l|l|l|}
\hline Ni1-N21 & $2.0442(16)$ & Ni1-O13 & $2.0978(12)$ \\
\hline Ni1-N12 & $2.0764(16)$ & Ni1-N11 & $2.1091(16)$ \\
\hline Ni1-N22 & $2.0776(15)$ & Ni1-O1W & $2.1454(14)$ \\
\hline & & & \\
\hline N21-Ni1-N12 & $176.60(6)$ & N22-Ni1-N11 & $96.46(6)$ \\
\hline N21-Ni1-N22 & $96.18(6)$ & O13-Ni1-N11 & $172.82(6)$ \\
\hline N12-Ni1-N22 & $80.46(6)$ & N21-Ni1-O1W & $90.32(6)$ \\
\hline N21-Ni1-O13 & $92.64(6)$ & N12-Ni1-O1W & $93.06(6)$ \\
\hline N12-Ni1-O13 & $87.78(6)$ & N22-Ni1-O1W & $173.12(6)$ \\
\hline N22-Ni1-O13 & $88.06(5)$ & O13-Ni1-O1W & $89.38(5)$ \\
\hline N21-Ni1-N11 & $81.36(6)$ & N11-Ni1-O1W & $86.74(6)$ \\
\hline N12-Ni1-N11 & $98.44(7)$ & & \\
\hline
\end{tabular}

Table 3: Hydrogen-bond geometry $\left(\AA,^{\circ}\right)$

\begin{tabular}{|l|l|c|c|c|c|}
\hline Code & $D-\mathrm{H} \cdots A$ & $D-\mathrm{H}$ & $\mathrm{H} \cdots A$ & $D \cdots A$ & $D-\mathrm{H} \cdots A$ \\
\hline$\# 1$ & $\mathrm{O} 2 W-\mathrm{H} 2 W B \cdots \mathrm{O} 3 W^{\mathrm{i}}$ & $0.84(1)$ & $2.02(1)$ & $2.832(2)$ & $164(3)$ \\
\hline$\# 2$ & $\mathrm{O} 3 W-\mathrm{H} 3 W A \cdots \mathrm{O} 2 W$ & $0.85(1)$ & $1.91(1)$ & $2.757(2)$ & $174(3)$ \\
\hline$\# 3$ & $\mathrm{O} 3 W-\mathrm{H} 3 W B \cdots \mathrm{O} 4 W$ & $0.85(1)$ & $1.94(1)$ & $2.777(3)$ & $170(3)$ \\
\hline$\# 4$ & $\mathrm{O} 4 W-\mathrm{H} 4 W A \cdots \mathrm{O} 5 W$ & $0.85(1)$ & $2.09(2)$ & $2.891(3)$ & $157(4)$ \\
\hline$\# 5$ & $\mathrm{O} 4 W-\mathrm{H} 4 W B \cdots \mathrm{O} 6 W^{\mathrm{ii}}$ & $0.85(1)$ & $1.98(2)$ & $2.807(3)$ & $165(4)$ \\
\hline$\# 6$ & $\mathrm{O} 5 W-\mathrm{H} 5 W B \cdots \mathrm{O} 6 W$ & $0.85(1)$ & $1.99(1)$ & $2.827(3)$ & $168(3)$ \\
\hline$\# 7$ & $\mathrm{~N} 11-\mathrm{H} 11 B \cdots \mathrm{O} 43^{\mathrm{iii}}$ & $0.91(2)$ & $2.33(2)$ & $3.213(2)$ & $163(2)$ \\
\hline$\# 8$ & $\mathrm{~N} 12-\mathrm{H} 12 A \cdots \mathrm{O} 33$ & $0.86(2)$ & $2.22(2)$ & $3.079(2)$ & $173(2)$ \\
\hline$\# 9$ & $\mathrm{~N} 12-\mathrm{H} 12 B \cdots \mathrm{O} 23^{\mathrm{iii}}$ & $0.87(2)$ & $2.36(2)$ & $3.085(2)$ & $140.8(19)$ \\
\hline$\# 10$ & $\mathrm{~N} 12-\mathrm{H} 12 B \cdots \mathrm{O} 33^{\mathrm{iii}}$ & $0.87(2)$ & $2.41(2)$ & $3.134(2)$ & $141.3(19)$ \\
\hline$\# 11$ & $\mathrm{O} 1 W-\mathrm{H} 1 W A \cdots \mathrm{O} 33^{\mathrm{iii}}$ & $0.84(1)$ & $1.83(1)$ & $2.6671(18)$ & $172(2)$ \\
\hline$\# 12$ & $\mathrm{O} 1 W-\mathrm{H} 1 W B \cdots \mathrm{O} 23$ & $0.84(1)$ & $1.80(1)$ & $2.6328(18)$ & $168(2)$ \\
\hline$\# 13$ & $\mathrm{~N} 11-\mathrm{H} 11 A \cdots \mathrm{O} 3 W^{\mathrm{iv}}$ & $0.86(2)$ & $2.21(3)$ & $3.053(2)$ & $169(2)$ \\
\hline$\# 14$ & $\mathrm{O} 2 W-\mathrm{H} 2 W A \cdots \mathrm{O} 23^{\mathrm{v}}$ & $0.84(1)$ & $1.95(1)$ & $2.792(2)$ & $175(2)$ \\
\hline$\# 15$ & $\mathrm{O} 5 W-\mathrm{H} 5 W A \cdots \mathrm{O} 43^{\mathrm{vi}}$ & $0.86(1)$ & $2.09(2)$ & $2.894(2)$ & $156(3)$ \\
\hline$\# 16$ & $\mathrm{O} 6 W-\mathrm{H} 6 W A \cdots \mathrm{O} 43^{\mathrm{vii}}$ & $0.86(1)$ & $1.91(1)$ & $2.762(2)$ & $172(3)$ \\
\hline$\# 17$ & $\mathrm{O} 6 W-\mathrm{H} 6 W B \cdots \mathrm{O} 1 W^{\mathrm{v}}$ & $0.86(1)$ & $2.02(2)$ & $2.806(2)$ & $151(2)$ \\
\hline
\end{tabular}

Symmetry codes: (i) $-\mathrm{x},-\mathrm{y}+1,-\mathrm{z}$; (ii) $\mathrm{x}-1 / 2,-\mathrm{y}+1 / 2, \mathrm{z}-1 / 2$; (iii) $-\mathrm{x}+2$, $-\mathrm{y}$, $\mathrm{z}$; (iv) $\mathrm{x}+3 / 2,-\mathrm{y}+1 / 2, \mathrm{z}+1 / 2$; (v) $\mathrm{x}-1 / 2,-\mathrm{y}+1 / 2, \mathrm{z}+1 / 2$; (vi) $-\mathrm{x}+1,-\mathrm{y},-\mathrm{z}$; (vii) $\mathrm{x}+3 / 2, \mathrm{y}+1 / 2,-\mathrm{z}+1 / 2$. 
The binuclear complex (Fig. 1) crystallizes in $P 2_{1} / \mathrm{n}$ with $Z^{\prime}=1 / 2$, and consists of two centrosymmetric Ni octahedral units linked by a bridging btc ligand halved by an inversion center. Each $\mathrm{Ni}$ cation coordinates two chelating $\kappa^{2} \mathrm{~N}, \mathrm{~N}^{\prime} a m p$ ligands, a bridging $\mu_{2} \mathrm{~K}^{2} \mathrm{O}, \mathrm{O}^{\prime}$ btc and one coordinated water molecule. The complex formulation is completed by an extremely large number of water solvates, 5 independent molecules, 10 in all for each binuclear unit. Molecular bond distances and angles are featureless, and will not be discussed (Table 2 shows the rather regular coordination distances and angles in the $\mathrm{Ni}$ polyhedron).

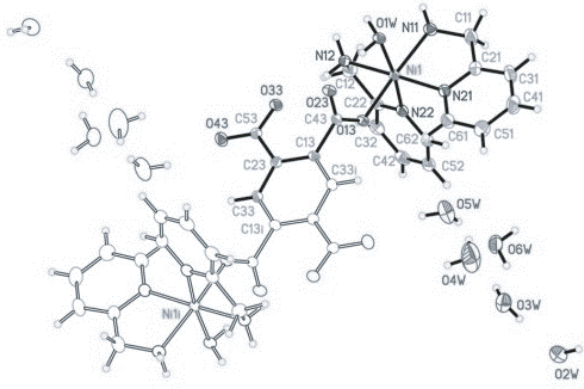

Fig. 1. The dinuclear unit in (1). (Displacement factors at a 50\% level).

The most interesting feature in the structure is the way in which the supra-molecular assembly is made up. The extremely large solvate part of the structure (O2W to $\mathrm{O} 5 \mathrm{~W})$ conforms a dense, crooked 2D network parallel to (100), via H-bonds \#1 to \#6 in Table 3 , made up by small $\left(\mathrm{R}_{4}{ }_{4}(8)\right)$ and large $\left(\mathrm{R}_{20}^{20}(40)\right)$ rings (Fig. 2a and $2 \mathrm{~b}$ ).

On the other hand, the complexes interact with each other through the $\mathrm{H}$ bonds having O1W, N11 and N12 as donors (\#7 to \#12 in Table 3), forming chains parallel to [100] (Figs $3 \mathrm{a}$ and $3 \mathrm{~b}$ ).

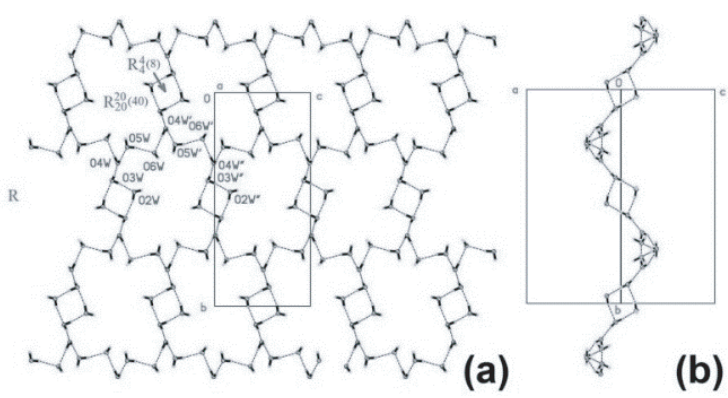

Fig. 2. a) The (100) solvato net, projected along [100]. b) a Sideways view, showing the undulating character of the $2 \mathrm{D}$ substructure.

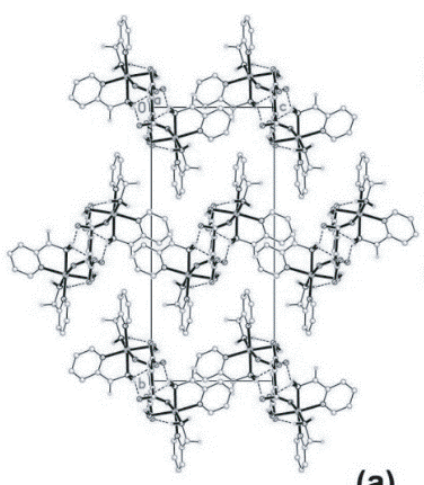

(a)

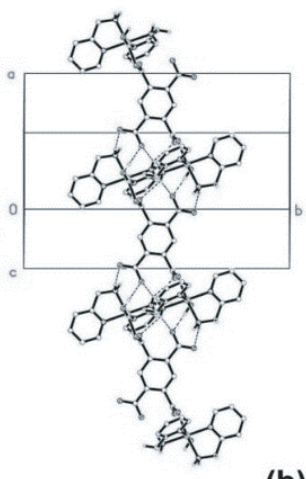

(b)
Fig. 3. The 1D structure defined by the complex molecules a) in a [100] view b) showing one single chain in detail.
These 1D substructures, in turn, "pierce" the (100) solvate network through the large $\left(\mathrm{R}^{20}{ }_{20}(40)\right)$ "square" holes, both substructures interacting strongly through H-bonds \#13 to \#17 in Table 3, defining a densely packed 3D structure.

The magnetic properties of $\left[\mathrm{Ni}_{2}(\text { amp })_{4}(\right.$ btc $\left.)\left(\mathrm{H}_{2} \mathrm{O}\right)_{2}\right] \cdot 10 \mathrm{H}_{2} \mathrm{O}$ (1) were determined by magnetic susceptibility measurements performed as a function of temperature in the range $2-300 \mathrm{~K}$. Figure 4 (a) shows a plot of $\chi_{\mathrm{M}}{ }^{-1} \mathrm{vs} T$, in the whole temperature range. The susceptibility data obeys the Curie Weiss law with a negative Weiss constant $\theta=-1.81 \mathrm{~K}$. This value is indicative of weak antiferromagnetic interactions.

Figure 4 (b) shows the magnetic behaviour of complex (1) in the form of the thermal variation of the product $\chi_{M} T$. This product is almost constant between 300 and $20 \mathrm{~K}$, but it undergoes a sharp decrease at low temperatures indicating weak antiferromagnetic interactions between the paramagnetic centers.
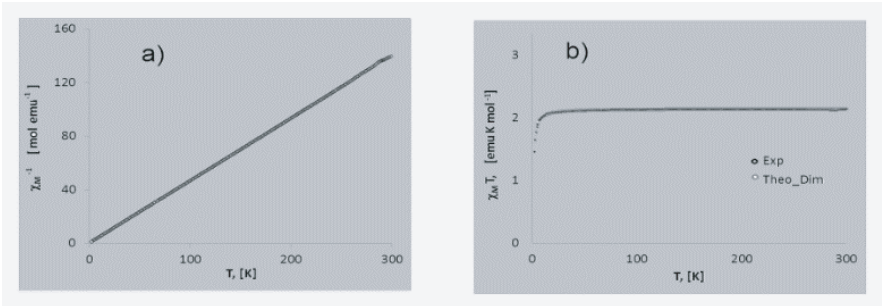

Fig.4. Magnetic behavior of complex (1) a) Temperature dependence of $\chi_{M}{ }^{-1}$ b) Temperature dependence of $\chi_{M} T$ in the range from 2 to $300 \mathrm{~K}$.

The calculated magnetic moment, in the $20 \mathrm{~K}<\mathrm{T}<300 \mathrm{~K}$ range, is $\mu=2.92$ $\mu_{\mathrm{B}}$, a value which is close to the spin only value $\left(2.84 \mu_{\mathrm{B}}\right)$ for an isolated $\mathrm{Ni}^{2+}$ ion.

As discussed above, the X-ray diffraction data show an intramolecular Ni (II)-Ni (II) distance of $11.48 \AA$ in the elongated dimer, corresponding to the whole span of the btc linker. This value is too large for a significant magnetic interaction but, due to the particular geometry of the elongated groups, the magnetic centers can approach each other to reach interdimeric Ni (II) -Ni (II) distances of $6.27 \AA$ (Scheme 3 ) mediated by a profuse H-bonding web. It appears quite reasonable then to think that this path is responsible for such weak magnetic interactions.

The proposed analytical expression to fit the experimental data considers two interacting $\mathrm{S}=1$ centers and is given by the isotropic single-spin model, with Hamiltonian [17].

$$
\widehat{H}=-J \widehat{S}_{A} \cdot \widehat{S}_{B}
$$

Therefore, the susceptibility expression can be written as:

$$
\chi_{M}=\frac{6 K}{\left(T-\theta_{N-\operatorname{dim}}\right)}\left[\frac{\mathrm{x}^{4}+5}{\mathrm{x}^{6}+3 \mathrm{x}^{4}+5}\right](1-\rho)+\rho\left[\frac{2 \mathrm{Ng}^{2} \beta^{2}}{3 \mathrm{k}\left(\mathrm{T}-\theta_{\mathrm{N}-\mathrm{mon}}\right)}\right]+\mathrm{N} \alpha
$$

where $x=\exp \left(\frac{J}{k T}\right), K=\frac{\mathrm{Ng}^{2} \beta^{2}}{3 k}, \rho=$ monomeric fraction, whereas the other terms have their usual meaning.

A least squares fit of the experimental data by equation (1) gives $\mathrm{J}=-3.5 \mathrm{~cm}^{-1}, \mathrm{~g}=2.13, \theta_{\mathrm{N}-\mathrm{dimer}}=-0.7 \mathrm{~K}, \theta_{\mathrm{N}-\mathrm{mon}}=0 \mathrm{~K}, \rho=0.15, \mathrm{~N} \alpha=2 \cdot 10^{-7}$. The agreement factor, $\mathrm{R}=\sum\left(\chi_{\mathrm{obs}}-\chi_{\mathrm{cal}}\right)^{2} / \Sigma\left(\chi_{\mathrm{obs}}\right)^{2}$ is $2.4 \cdot 10^{-4}$.

The small negative exchange coupling constant $\mathrm{J}$ is consistent with the long distance between both nickel ions $(11.48 \AA)$ and confirms the antiferromagnetic character of the compound.

In a magnetic study of $\mathrm{Ni}$ (II) centers in an octahedral environment with weak antiferromagnetic behavior, one parameter to be considered is the zerofield splitting (D) [18]. Results reported in the literature indicate sometimes that the inclusion of this term improves the quality of the magnetic fits but does not significantly alter the values of the exchange constant $J$ or the calculated value of g. In this respect Prushan et al.[19] reported the synthesis and magnetic characterization of a dinuclear nickel (II) complex formulated as $\left[\mathrm{Ni}(\text { dpmap })\left(\mathrm{H}_{2} \mathrm{O}\right)\right]_{2}\left(\mathrm{ClO}_{4}\right)_{2} \cdot 3\left(\mathrm{CH}_{3}\right)_{2} \mathrm{CO}$ (2) where dpmap is $2-\{[[\mathrm{Di}(2-$ pyridyl)methyl](methyl)amino]methyl $\}$ phenol. In this complex, two anionic dpmap ligands bridge two $\mathrm{Ni}(\mathrm{II})$ centers via $\mu_{2}$-phenolate oxygen donor. 
Both nickel(II) centers have distorted octahedral symmetry. The complex exhibited an antiferromagnetic behavior. The magnetic susceptibility data were adjusted to a model derived from Kambe's method that includes the zero field splitting $\left(\mathrm{D}=-1.6 \mathrm{~cm}^{-1}\right)$ giving values of $\mathrm{J}=-0.85 \mathrm{~cm}^{-1}, \mathrm{~g}=2.26$. The authors indicate that, not including the term $\mathrm{D}$ in the adjustment model, it results in almost identical values of J and $\mathrm{g}$ [19].

This result is similar to that found in the complexes $\left[\mathrm{Ni}_{2}(P M T A)(\text { bipy })_{4}\right](3)$ and $\left[\mathrm{Ni}_{2}(P M T A)(\text { phen })_{4}\right]$ (4) informed by Li et al. [20] (where L denotes 2,2'bipyridine (bpy), or 1,10-phenanthroline (phen) and PMTA is the tetra-anion of pyromellitic acid). The complexes have a dimeric structure where PMTA acts as a bridging ligand. The coordination environment around each nickel atom was described as distorted octahedral. Both complexes exhibited antiferromagnetic exchange interactions with $\mathrm{J}=-0.98 \mathrm{~cm}^{-1}, \mathrm{~g}=2.18$ for $(\mathbf{3})$ and $\mathrm{J}=-1.16 \mathrm{~cm}^{-1}$, $\mathrm{g}=2.14$ for (4). The authors indicated that, when considering the zero-field splitting in the calculations, a much better fit of the experimental data was obtained, but the values of $\mathrm{J}$ and $\mathrm{g}$ remained essentially unchanged. The values obtained in this case were $\mathrm{J}=-0.95 \mathrm{~cm}^{-1}, \mathrm{~g}=2.16, \mathrm{D}=-1.9 \mathrm{~cm}^{-1}$ for $(3)$ and $\mathrm{J}=-1.20 \mathrm{~cm}^{-1}, \mathrm{~g}=2.15$ and $\mathrm{D}=-1.8 \mathrm{~cm}^{-1}$ for $(\mathbf{4})$.

\section{Final remarks}

There is scarce information in the literature regarding magnetic properties of $\mathrm{Ni}(\mathrm{II})$ complexes with carboxylate bridges similar to (1). In the examples $\left[\mathrm{Ni}_{2}(P M T A)(\text { bipy })_{4}\right]$ (3) and $\left.\left[\mathrm{Ni}_{2}(P M T A) \text { (phen }\right)_{4}\right]$ (4) discussed above, the complexes presented weak magnetic coupling, with $\mathrm{J}=-0.98 \mathrm{~cm}^{-1}$ and $-1.16 \mathrm{~cm}^{-1}$ respectively [20]. This type of behaviour was also observed in complexes with a dicarboxylic bridge, as $\left[\mathrm{Ni}_{2}(\right.$ tp $\left.)(\text { pren })_{4}(\mathrm{Him})\right]\left(\mathrm{ClO}_{4}\right)_{2}(\mathbf{5})$ where pren $=1,3$-diaminopropane Him $=$ imidazole, $t p=$ therephthalate, reported by Xiao-Ming Chen and coworkers [21]. This complex consisted in two octahedral $\mathrm{Ni}(\mathrm{II})$ centers, $11.505 \AA$ apart and bridged by a tp dianion where both carboxylates act as monodentate. The small interchange constant $\mathrm{J}=-0.7 \mathrm{~cm}^{-1}$ indicated a weak antiferromagnetic interaction.

Another example of this type is the $\left[\mathrm{Ni}_{2}(\text { cth })_{2}(\mu-T P H A)\right] \cdot\left(\mathrm{ClO}_{4}\right)_{2}$ (6) complex where cth is rac-5,7,7,12,14,14-hexamethyl-1,4,8,11tetraazacyclotetradecane and TPHA is the dianion from terephtalic acid, reported by En Qing Gao et al. [22]. In this complex, the Ni(II) ions occupy distorted octahedral environments, linked by the carboxylate groups of the terephtalic ligand, acting in a bidentate fashion. In this case, the complex was also antiferromagnetic, with an interchange constant $\mathrm{J}=-0.33 \mathrm{~cm}^{-1}$.

At first glance all these results would suggest that this type of bridging would not favor the magnetic interchange due to the unfavourably large interdimeric distances $(>10 \AA)$ but, on the other hand, Wieghardt and coworkers [23] have found in their studies of $\mathrm{Cu}(\mathrm{II})$ complexes that rather strong magnetic couplings may arise along large distances, through adequate orbital paths.

Thus, the behaviour is not clear and leaves the unavoidable conclusion that a thorough magneto-structural study in a $\left[\mathrm{Ni}_{2}(\mu-b t c)(\mathrm{L})_{4}\right]$ homologous series is needed to better understand the magnetic phenomena in this type of complexes.

\section{DATA AVAILABILITY}

The data used to support the findings of this study are available from the corresponding author upon request.

\section{CONFLICT OF INTEREST}

The authors declare that there is no conflict of interest regarding the publication of this paper.

\section{ACKNOWLEDGEMENTS}

This work has been performed as part of the Chilean-French International Associated Laboratory for Multifunctional Molecules and Materials LIA-M3CNRS $\mathrm{N}^{\circ} 1027$ ), for its help in the mobility of researchers

\section{SUPPLEMENTARY MATERIALS}

Diffraction data (.CIF file) are available on the journal's website (Supplementary Materials).

\section{REFERENCES}

1. L. Carneiro, A. R. Silva, P. S. Shuttleworth, V. Budarin and J. H.Clark, $\begin{array}{lllll}\text { Molecules, } 19 & \text { (8), } & \text { pp } & \text { 11988-11998 }\end{array}$ doi.org/10.3390/molecules190811988

2. G H. Le Bozec, T. Renouard, Eur. J. Inorg. Chem., pp 229-239 (2000), doi.org/10.1002/(SICI)1099-0682(200002)2000:2<229::AIDEJIC229>3.0.CO;2-A

3. Ch-Ch. Wang, Y-Q. Zhang, T. Zhu, X-Y. Zhang, S-J. Gao, Polyhedron, 90, pp 58-68 (2015), doi.org/10.1016/j.poly.2015.01.042; A.M. Aref, A. I. El-Said, R. Gabr, R. A. Mukred., American Chemical Science Journal, 6(3), pp 144-157( 2015), doi.10.9734/ACSJ/2015/15754

4. K. L. Haas and K. J. Franz, Chem Rev., 109 (10), pp 4921-4960 (2009), doi: 10.1021/cr900134a; Ch-Ti Chen, K. S.Suslick., Coordination Chemistry Reviews. 128, pp 293-322 (1993), doi.org/10.1016/0010-8545(93)80036-5

5. D.Q Chu, J.Q. Xu, L. M.,Wang, A.Q.Tang,1.Ye, Eur. J. Inorg. Chem., pp 1135 1137. (2001), doi.org/10.1002/1099-0682(200105)2001:5<1135::AIDEJIC1135>3.0.CO;2-G; Y. Wu, C. Xia, J. Qian , J. Xie, J. Chem. Sci. 129 (8), pp 1183-1191(2017), doi 10.1007/s12039-017-1319-x

6. Y. B Go, X_Wang, EV Anokhina, A.J. Jacobson, Inorg. Chem., 44 , pp 82658271 (2005), doi: $10.1021 /$ ic $050644 d$

7. F. Rochon Fernande, G.Massarweh, Inorg. Chim. Acta, 304, pp 190-198 (2000), doi.org/10.1016/S0020-1693(00)00086-4

8. A.M. Atria, M. T.Garland, R. Baggio, Acta Cryst., C70, pp 541-546 (2014), doi:10.1107/S2053229614008134

9. R.J. Doedens , Prog. Inorg. Chem., 21, pp 209-231 (1976), doi.org/10.1002/9780470166222.ch9; Y-Z. Zheng, Z. Zhenga, X-M. Chen, Coordination Chemistry Reviews, 258-259 pp 1-15(2014), doi: 10.1016/j.ccr.2013.08.031

10. M. Kurmoo., Chem. Soc. Rev., 38 pp 1353-1379 (2009), doi:10.1039/B804757J: N. R. de Campos, M. A. Ribeiro, W. X. C. Oliveira, D. O. Reis,H. O. Stumpf, A.C., Doriguetto, F. C. Machado,C. B. Pinheiro, F. Lloret, M. Julve, J. Cano, M. V. Marinho, Dalton Trans., 45, pp172-189 (2016), doi: $10.1039 / \mathrm{c} 5 \mathrm{dt} 03401 \mathrm{a}$

11. S. Sen, M.K Saha, T. Gupta, A.K. Karmakar, P. Kundu, S. Mitra, M.B. Hursthouse, K. M. A. Malik, Journal of Chemical Crystallography, 28, pp 771-777 (1998), doi.org/10.1023/A:102182072

12. E. Colacio, J. M. Domínguez-Vera, M. Ghazi, R. Kivekäs, M. Klinga, J. M.Moreno, Eur. J. Inorg. Chem. pp 441- 445 (1999), doi.org/10.1002/(SICI)1099-0682(199903)1999:3<441::AIDEJIC441>3.0.CO;2-T

13. Bruker SMART, V5.624. Data Collection Software. Siemens Analytical X-ray, Instruments Inc., Madison, Wisconsin, USA. (2001).

14. Bruker (SAINT, V6.22A (Including SADABS). Data Reduction Software.Siemens., Analytical X-ray Instruments Inc., Madison, Wisconsin, USA.( 2002).

15. G.M. Sheldrick, Acta Cryst., A64, pp 112-122 (2008), doi.org/10.1107/S0108767307043930

16. G. M Sheldrick, Acta Cryst., C71, pp 3-8 (2015), doi.org/10.1107/S2053229614024218

17. Earnshaw, Introduction to magnetochemistry, Academic Press, London (1968)

18. G. De Munno, T. Poerio, M. Julve, F. Lloret, A. Derory, J. Chem. Soc. Dalton Trans., pp 1179-1184 (1993), doi:10.1039/DT9930001179

19. M. J. Prushan, D. M. Tomezsko, S. Lofland, M. Zeller, A. D. Hunter, Inorg. Chim. Acta, 360 pp 2245-2254(2007), doi.org/10.1016/j.ica.2006.11.008

20. Y.-T. Li, C.- W. Yan, Ch.- S. Xu, D.- Z. Liao., Synth. React. Inorg. Met. Org. Chem., 28:3, pp 367-381(1998), doi.org/10.1080/00945719809349361

21. H.-L. Zhu, Y.-X. Tong, X.-M. Chen, Ch.-X. Ren., Trans. Metal Chem., 26, pp. 528-531 (2001), doi.org/10.1023/A:1011011422776

22. E.-Q. Gao, Q.-H. Zhao, J.-K. Tang, D.-Z. Liao, Z.-H. Jiang, S.-P. Yan, J. Coord. Chem., 55:2, pp 205-213 (2002), doi.org/10.1080/00958970211878

23. K. S. Bürger, P. Chaudhuri, K. Wieghardt, B. Nuber, Chem. Eur. J. 1pp. 583593 (1995), doi.org/10.1002/chem.19950010904 